\title{
No tabuleiro de xadrez: Beckett e Duchamp
}

Juan Manuel Terenzi

UFSC

\begin{abstract}
Resumo
O presente artigo parte de um inusitado encontro (1940) entre o artista francês Marcel Duchamp e o escritor irlandês Samuel Beckett na cidade de Arcachon, no sudoeste da França. Tal encontro é ocasionado em virtude do desencadeamento da invasão nazista a Paris, bem como pelo interesse que ambos manifestavam pelo jogo de xadrez. Primeiramente, aludimos brevemente a relação do jogo com a literatura e com a filosofia, para depois efetuarmos a leitura de Fim de Jogo de Beckett, peça fundamental dentro da poética beckettiana - levando em conta que ela foi escrita e encenada após a segunda guerra - a partir de alguns pressupostos enxadrísticos referentes à terceira fase do jogo de xadrez (denominada justamente de fim de jogo) por parte de Duchamp.

Palavras-chave: Beckett; Duchamp; Literatura; Xadrez.
\end{abstract}

\begin{abstract}
The present article explores an unusual meeting (1940) between the French artist Marcel Duchamp and the Irish writer Samuel Beckett at Arcachon, southwest region of France. This meeting is only possible because of the Nazi invasion of Paris, as well as the interest both manifested for the game of chess. First of all, we briefly make allusion to the relation of the game with literature and philosophy, then we read the Beckett`s piece Endgame, a fundamental work in his poetics - taking into account it was written and staged after the Second World War - from some chess assumptions referred to the third moment of a game of chess (namely the endgame) of Duchamp.
\end{abstract}

Keywords: Beckett; Duchamp; Literature; Chess. 
1. HERÁCLITO. In: Presocráticos.

Fragmentos I, 2008, p. 221. O verbo utilizado em grego é pesseúo, cujo significado literal seria o de jogar dados, tal qual aparece na tradução. De fato, este elemento do acaso, da sorte, de não pertencimento ao puro jogo intelectual que vigora no seu formato atual, esteve presente nas origens do xadrez, uma vez que o movimento das peças dependia dos dados lançados ao ar e do subsequente número que se fazia ver, acarretando no movimento da peça. Inevitável fazermos a comparação com Mallarmé e seu jogo de dados que jamais abolirá o acaso ("Un coup de dés jamais n'abolira le hasard"). O xadrez buscaria extirpar o acaso de sua constituição lúdica, delimitando seu raio de ação apenas ao aspecto do cálculo e da lógica. Contudo, uma passagem do conto "Maelzel's Chess-Player" de Poe inverte esta asserção, ao comparar o cálculo frio da álgebra com o desenrolar de um jogo de xadrez, em que cada jogada multiplica as possibilidades de resposta de forma exponencial, propiciando que o jogo nunca esgote suas possibilidades: "But in proportion to the progress made in a game of chess, is uncertainty of each ensuing move. A few moves having been made, no step is certain". Isto é, no xadrez o elemento teleológico estaria enredado no acaso, diferentemente das equações matemáticas que conduzem a um resultado final.

\section{A palavra aïeul em francês} conserva o aión grego, e que na transcriação ao português por Haroldo de Campos, ainda pode ser lida e ouvida: "as águas pelo ancião tentando ou o ancião contra as águas/ uma chance ociosa" (grifo nosso). In: Mallarmé, 2010, p. 160.
It's a game, it's getting to be a game, I'm going to rise and go, if it's not me it will be someone, a phantom, long live all our phantoms, those of the dead, those of the living, and those of those who are not born.

Texts for Nothing 5, Samuel Beckett

Literatura, filosofia e xadrez possuem uma afinidade antiga. Como exemplo disto, podemos ler no fragmento 52 de Heráclito: "El tiempo vital (aiòn) es un niño que juega (paizon) tirando los dados (pesseúon); el reino de un niño"1. A respeito deste lançar de dados e da proximidade com o tempo vital, ou o tempo eterno, dependendo do contexto em que a palavra aparece, trazemos Mallarmé e seu poema dos dados, numa passagem que diz o seguinte: "la mer par l'aieul tentant ou l'aïeul contre la mer/ une chance oiseuse"2. A frase atribuída a Júlio César - Alea jacta est - literalmente, os dados estão lançados, ecoa no poeta francês.

Ainda próximos de nosso tempo, há uma série de escritores e filósofos que se debruçaram sobre o xadrez para servir-lhes de matéria de especulação e criação. Impossível abarcar todos, e para a presente finalidade fizemos um recorte. Como primeiro exemplo, advindo do seio da modernidade, Edgar Allan Poe problematiza e busca fazer objeções ao jogador-autômato que se difundira a partir do século XVIII, o conhecido Turco, mas que na verdade escondia dentro de sua complicada montagem um anão, cujos conhecimentos enxadrísticos colhiam vitórias e mais vitórias. Entre os derrotados, espanta ver os nomes de Napoleão Bonaparte e Benjamin Franklin ${ }^{3}$. Walter Benjamin, na primeira de suas teses sobre o conceito de História, recorda este autômato e de quem se escondia em sua estrutura complicada: " $\mathrm{Na}$ realidade, um anão corcunda se escondia nela, um mestre no xadrez, que dirigia com cordéis a mão do fantoche"4. Tal lembrança do autômato sustenta a crítica de Benjamin ao materialismo histórico, associado a Karl Marx.

A origem desse personagem denominado de Turco pode ser lida nas linhas que compõem o conto "Maelzel's ChessPlayer": "The Automaton Chess-Player was invented in 1769 by Baron Kempelen, a nobleman of Presburg, in Hungary, who afterward disposed it, together with the secret of its operation,

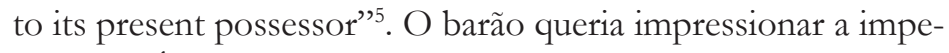
ratriz da Áustria, Maria Theresa, com o intuito de mostrar sua capacidade intelectiva, bem como seu enorme poderio, com a construção de uma máquina tão avançada, inclusive a mais alta inovação tecnológica até o momento (1769). Poe busca desde o início compreender o modus operandi desta suposta máquina, a fim de verificar que ela só pode ser fruto de uma mente (mind). Realmente, essa hipótese será levada a cabo: 
There can be no doubt, as we have before observed, and as we will presently endeavor to show, that the principle, or rather the result of this solution is the true one. Some person is concealed in the box during the whole time of exhibiting the interior. ${ }^{6}$

Vemos aqui a semente dos contos policiais de Poe, a busca por um elemento racional por detrás do fantástico. Mas por ser fruto justamente de uma mente, e não de uma máquina que calcula com exatidão, Poe incluirá o elemento de incerteza, como citamos na nota 2. Princípio de incerteza que mais tarde estará associado ao físico alemão ganhador do prêmio Nobel de 1932, Werner Heisenberg. Esta incerteza não está longe do que Jorge Luis Borges compôs em versos: "Dios mueve al jugador, y éste, la pieza. / ¿Qué dios detrás de Dios la trama empieza / de polvo y tiempo y sueño y agonías?" 7 . Ora, como dissolver-se, se assim se deseja ou, talvez, como experimentar e regozijar-se nessa malha na qual o próprio jogo nos enreda? Afinal, desde o primeiro movimento, o qual sempre se dá através das peças brancas, as possibilidades apenas se multiplicam. O primeiro lance pode ser um de vinte possíveis ${ }^{8}$, a resposta das negras outras vinte possibilidades, e assim sucedem-se as variantes, tornando o jogo uma potência ao infinito.

Como dito anteriormente, poder-se-iam citar inúmeros outros escritores e filósofos que moldaram sua escrita a partir do material fornecido pelo xadrez, como Lewis Carroll, Rodolfo Walsh, Henri Bergson (possui uma interessante analogia entre a memória e a imagem visual dos jogadores de xadrez às $\operatorname{cegas}^{9}$ ), Juan José Arreola, Stefan Zweig, William Faulkner, etc. Entretanto, para arrematar esta extensa lista e aproximando-nos de nosso objeto de estudo neste trabalho, selecionamos o filósofo austríaco Ludwig Wittgenstein para falar um pouco mais dessa relação entre filosofia e xadrez, ou mais especificamente, entre linguagem e xadrez. Afinal, Wittgenstein utilizara o xadrez e sua riqueza enquanto jogo para dar conta de muitas especulações acerca do funcionamento e do uso (Gebrauch) da linguagem.

Grosso modo, a sua filosofia é dividida em duas etapas, sendo que a primeira estaria representada pelo seu único livro publicado em vida - o Tractatus Logico-Philosophicus (1921), voltado ao aspecto lógico da linguagem, com nítidas influências de Frege e Russell. Neste livro Wittgenstein vincula a linguagem a uma figuração (Bildung), vindo a elaborar as conhecidas tabelas de verdade. Porém, a partir da década de 1930, haverá uma mudança na sua abordagem sobre o funcionamento da linguagem, acarretando no surgimento do conceito de jogo de linguagem (Sprachspiel). Elaborado de forma rudimentar já nos Cadernos Marrom e Azul, será com a publicação póstuma das Investigações Filosóficas (1951), a qual contrapõe-se desde o início a uma
3. O "massacre" perpetrado pelo Turco contra o imperador Napoleão Bonaparte pode ser visto em: http:/ /www. chessgames.com/perl/ chessgame?gid $=1250610$. No século XX, a vitória de uma máquina contra um humano encontra paralelo na vitória do computador Deep Blue contra Kasparov, sem esquecer que o primeiro jogo entre ambos fora selado por uma vitória do jogador do Azerbaijão.

4. BENJAMIN, Walter. Obras escolhidas. Magia e técnica, arte e politica, 1994, p. 222. No original: "In Wahrheit saß ein buckliger Zwerg darin, der ein Meister im Schachspiel war und die Hand der Puppe an Schnüren lenkte". Disponível em: http:/ /www. textlog.de/benjamin-begriffgeschichte.html

5. POE, Edgar Allan. The complete illustrated Works of Edgar Allan Poe, 2003, p. 693.

6. Ibidem, p. 693.

7. BORGES, Jorge Luis. "Ajedrez", 2008, p. 17.

8. As brancas podem iniciar ou com um movimento simples de peão (a3, b3... h3), ou um movimento duplo (a4, b4... h4), ou ainda com um de dois movimentos diversos de cada cavalo (para o cavalo situado em Cb1: Ca3 ou Cc3, e para o cavalo situado em Cg1: Cf3 ou Ch3).

9. Cf. BERGSON, Henri.

L'énergie spirituelle, 1967. 
10. Aqueles que denominam de terceiro Wittgenstein o autor das Investigações, consideram que seus livros de transição, especialmente os Cadernos Aqul e Marrom, representariam uma segunda etapa de seu pensamento.

11. WITTGENSTEIN, Ludwig. Philosophical Remarks, 1975a, p. 61.

12. WITTGENSTEIN, Ludwig. Investigações Filosóficas, 1975b, p. 26. No original: "Wenn man jemandem die Königsfigur im Schachspiel zeigt und sagt: "Das ist der Schachkönig", so erklärt man ihm dadurch nicht den Gebrauch dieser Figur - es sein denn, da $\beta$ er die Regeln des Spiels schon kennt, bis auf diese letzte Bestimmung: die Form einer Königsfigur. Man kann sich denken, er habe die Regeln des Spiels gelernt, ohne da $\beta$ ibm je eine wirkliche Spielfigur gezeigt wurde. Die Form der Spielfigur entspricht hier dem Klang, oder der Gestalt eines Wortes” (p. 15).

13. Baseamos esta leitura a partir do artigo de Harry Vandervlist intitulado "Beckett, Duchamp and Chess: A Crossroads at Arcachon in the Summer of 1940" e também através da biografia de Beckett Damned to fame: the life of Samuel Beckett de James Knowlson. concepção ostensiva da linguagem proveniente de Agostinho, que veremos a relação jogo e linguagem ser alargada e relacionada ao seu uso, à práxis mesmo da linguagem, caracterizando o que a crítica filosófica denomina de segundo, ou às vezes até de terceiro Wittgenstein ${ }^{10}$. Isto é, cada palavra adquire seu significado no contexto de uso em que se encontra. Nas Observações Filosóficas, anterior às Investigações, encontramos uma definição que perpassa todo o pensamento posterior do filósofo: "The question: 'What is a word?' is completely analogous with the question "What is a chessman?"11. Esta analogia entre a palavra e a peça de xadrez é de fato surpreendente, pois uma das definições de homem provenientes da Grécia Antiga é justamente a de possuir a capacidade de racionalizar e emitir palavras sobre o mundo, além do fato de que Kasparov, considerado um dos maiores enxadristas de todos os tempos, declarou ser o xadrez a representação da vida em miniatura. Logo, vida, linguagem e xadrez configurariam uma tríade especial.

Retornando à analogia feita por Wittgenstein, ela será desenvolvida com muito mais complexidade nas Investigações. Aqui, o filósofo irá tecer considerações determinantes sobre sua nova concepção filosófica forjando conceitos como jogos de linguagem, semelhança de família, a noção de seguir regras, o treinamento e o uso. Todos eles de alguma forma relacionados com o jogo de xadrez. A modo de exemplo, podemos ler no parágrafo $\$ 31$ o primeiro momento em que ele se vale do xadrez para efetuar uma analogia com a linguagem:

Quando se mostra a alguém a figura do rei (Königsfigur) no
jogo de xadrez e se diz: "Este é o rei do xadrez", não se elu-
cida por meio disso o uso (Gebrauch) dessa figura, a menos
que esse alguém já conheça as regras do jogo (die Regeln des
Spiels), até esta última determinação: a forma de uma figura
de rei. Pode-se pensar que já aprendera as regras do jogo,
sem que se lhe tenha mostrado uma figura real. A forma da
figura do jogo corresponde aqui ao tom (Klang), ou à confi-
guração (Gestalt) de uma palavra (eines Wortes). ${ }^{12}$

Feita esta breve apresentação, será através desta frutífera relação que estabeleceremos nossa leitura a partir de agora, escolhendo para este fim um encontro que se deu em plena segunda guerra mundial entre dois eminentes artistas.

Em meados de junho de 1940, Marcel Duchamp e Samuel Beckett decidem retirar-se de Paris. A cidade luz encontra-se ocupada pelas forças militares de Hitler e em face de tamanha violência resta uma opção. Ao longo de três meses, na localidade de Arcachon, eles jogarão xadrez, uma paixão compartilhada por ambos ${ }^{13}$. Distanciadas por aproximadamente 650 quilômetros, as cidades irão representar um contraste aparente em relação 
ao que ocorre no país, já que Arcachon estaria fora de perigo. Logo, Duchamp e Beckett assemelhar-se-iam aos jogadores de xadrez que nos põe em versos Ricardo Reis:

Ouvi contar que outrora, quando a Pérsia

Tinha não sei qual guerra,

Quando a invasão ardia na Cidade

$\mathrm{E}$ as mulheres gritavam,

Dois jogadores de xadrez jogavam

O seu jogo contínuo. ${ }^{14}$

Inclusive, se transpusermos as palavras como num anagrama, as letras constituintes da palavra Pérsia darão origem à palavra Paris, restando ainda o verbo ser conjugado na terceira pessoa do singular, indicando-nos enigmaticamente que "é" Paris a que sofre os ataques, mas "é" Arcachon, e seu clima litorâneo a cidade que acolhe os jogadores de xadrez. Não obstante, diferentemente do poema, embora muitas mulheres seguramente gritem em Paris, ao lado dos enxadristas também estão seus pares femininos ${ }^{15}$. Nesses três meses de refúgio bélico, Duchamp e Beckett permearão o tabuleiro de sessenta e quatro casas, alternadamente brancas e negras, com suas jogadas. Buscarão racionalizar em meio a um momento difícil na história mundial, nesse que é tido como um jogo cujas fontes da fortuna e do azar estão supostamente eliminadas. Tal aspecto cartesiano do xadrez pode ser associado aos dois artistas:

Although he once said that he had "never read Descartes, to speak of", Duchamp admitted to being "very much of a Cartesian". Cartesian doubt lay behind his habit of questioning every previous definition of art, so that, as he put it, "doubting everything, I had to find something that gave me no doubt because it didn't exist before. All along, I have searched for what I have not thought of before". ${ }^{16}$

Por sua vez, não podemos ignorar que Beckett também se sentia atraído, ou ao menos o usava como material literário, pelo filósofo do cogito:

The Cartesian qualities of chess might well have been part of Beckett's attraction to the game as well. Descartes fascinated Beckett to such a degree that his first published poem "Whoroscope" dealt with obscure details of the philosopher's biography. His novel Murphy can be read in part as a satire on the quizzical and opportunistic Cartesianism of its protagonist. ${ }^{17}$

Além disso, o xadrez também possui a peculiar característica de hipnotizar os jogadores envolvidos, como o mesmo Ricardo Reis nos canta:
14. PESSOA, Fernando. Obra poética, 2005, p. 65.

15. Nas palavras de Vandervlist: "From mid-June to September of that year, they passed several weeks in Arcachon, near Bordeaux, with their companions Mary Reynolds and Suzanne Deschevaux-Dumesnil”. In: VANDERVLIST, H. "Beckett, Duchamp and Chess: A

Crossroads at Arcachon in the summer of 1940". Anglophonial Caliban, 33/2013, p. 175.

16. Ibidem, p. 177.

17. Ibidem, p. 177. 
18. PESSOA, Fernando. Obra poética, 2005, p. 269.

19. MARTÍNEZ ESTRADA, Ezequiel. Filosofia del ajedrez, 2008 , p. 31.

20. Disponível no site: https://www.youtube.com/ watch? $\mathrm{v}=\mathrm{TN} 6 \mathrm{~m} 711 \mathrm{ddZk}$
E, enquanto lá fora,

Ou perto ou longe, a guerra e a pátria e a vida

Que em vão nos chamem, cada um de nós

Sob as sombras amigas

Sonhando, ele os parceiros, e o xadrez

A sua indiferença. ${ }^{18}$

Compartilhando esta descrição dos jogadores de xadrez, afirma Martínez Estrada, escritor argentino e aficionado pelo xadrez: "Este poder de concentración y absorción en el ajedrez es tan grande que ha dado margen a un vasto anecdotario en que los jugadores aparecen como hipnotizados, sin advertir el derrumbamiento de la habitación donde están o el incendio de su silla"19. Este momento de arrebatamento do jogador de xadrez encontra uma bela adaptação cinematográfica no filme Shakbmatnaya goryachka $a^{20}$ (Chess Fever, 1925) dos diretores russos Pudovkin e Chpikovski.

Voltando ao caráter cartesiano do xadrez, se pensarmos nas três fases em que se costuma dividir o desenvolvimento do jogo - abertura, meio-jogo e final - é justamente no final de jogo em que sobressaem as qualidades racionais e calculistas do jogo, uma vez que aqui não há muito espaço para elaborações criativas, embora não possamos reduzi-las a zero. Reside nesta divisão uma chave para a leitura de Fin de partie, peça beckettiana fundamental dentro do cenário literário beckettiano, e que lida com esse momento do jogo - o final ou fim de jogo (Fin de partie / Endgame), especificamente numa posição em que pode terminar em empate. Todavia, sigamos na esteira deste encontro singular.

Remetendo-nos agora ao contexto histórico, ou seja, ao ano de 1940, efetuando um breve trajeto cronológico, verificaremos que Duchamp havia já publicado, juntamente com Vitaly Halberstadt - enxadrista profissional, problemista e criador de estudos sobre finais - o livro L'Opposition et Cases Conjuguées sont Réconciliées (1932), enquanto Samuel Beckett publicara Murphy (1938), traduzindo-o ao francês somente em 1948, quando a segunda guerra estava consumada. Assim, ambos haviam manifestado em letra impressa sua relação com o jogo de xadrez. Duchamp de maneira mais profissional, enquanto Beckett vertia em literatura a afeição que experimentava pelo jogo milenar.

Aqui vale a pena fazer um breve parêntese a fim de destacar qual o vínculo que cada um deles estabelecera com o xadrez, pois como dito anteriormente, Duchamp fora um jogador profissional, inclusive representando a equipe francesa de xadrez nas Olimpíadas em cinco oportunidades. A década de 1920 fora a mais próspera para Duchamp no que concerne ao jogo, alcançando uma destreza de alto nível, tornando-se campeão citadino (Paris). Em linhas gerais, o artista francês realmente dedicara muito tempo e esforço para poder enfrentar-se com 
os maiores jogadores de sua época, e apesar de sofrer muitas derrotas, jogadores como Emmanuel Lasker afirmavam que seu jogo era "muito sólido". Contudo, devem ser mencionadas também as várias manifestações do xadrez no trabalho artístico de Duchamp, principalmente aquela imagem em que ele aparece jogando contra uma jogadora - Eve Babitz - despida, numa contraposição de cores, pois Duchamp vestido de preto joga com as peças brancas, e Babitz exibindo sua tez alva manipula as peças negras. Todavia, optaremos por enfocar, sobretudo, a literatura de Beckett, cientes da riqueza que o xadrez representa na obra de Duchamp ${ }^{21}$.

Seguindo com o escritor irlandês, ele aprendera a mover as peças com um tio seu, Howard, que derrotara o enxadrista cubano José Raúl Capablanca numa exibição de simultâneas. Porém, o escritor irlandês nunca participou de um campeonato de xadrez, relegando sua paixão aos seus escritos, nomeadamente nos textos Murphy e Fin de Partie.

Interessante notar que Murphy alude quase de forma homônima a Paul Morphy (1837-1884), um dos jogadores de xadrez mais fortes de todos os tempos, mas que não fora consagrado campeão, pois em seu tempo ainda não estavam oficializados os campeonatos mundiais de xadrez. Ironicamente, Morphy morre de maneira trágica, consumido pela depressão, delirando com imagens visíveis apenas em seu universo atormentado. Não é raro acompanhar este tipo de manifestação psíquica em jogadores de xadrez de alto nível, e Morphy fora mais uma vítima de um colapso mental. Entretanto, o que gostaríamos de destacar é a relação do xadrez e da literatura que se encontra em Fin de partie, peça dramática de Beckett publicada e encenada em 1957. Dezessete anos após aquele encontro em Arcachon, Beckett publica sua peça levando em consideração aquilo que Duchamp e Halberstadt discutiram no livro publicado em 1932 - uma determinada configuração das peças no tabuleiro, especificamente o rei acompanhado de um peão dispostos de tal maneira que o máximo que as negras podem obter é um empate, enquanto a vitória para as brancas se dá ou por meio de um complicado número de movimentos, ou por erros das negras.

Nas palavras de Hugill: "In conclusion, it will be observed that the most Black can hope for is a draw. Given accurate play by White, Black can only succeed in delaying the progress of events" "22. Mas o que mais chama a nossa atenção é quão rara esta posição ocorre nos jogos, e de acordo com o próprio Duchamp: "The endgames in which it works would interest no chess player... even the chess champions don't read the book, since the problem it poses only comes up once in a lifetime. They're end-game problems of possible games but so rare as to be nearly Utopian" ${ }^{23}$.
21. Aqui é imprescindível citar o livro do professor e pesquisador Raul Antelo, Maria com Marcel: Duchamp nos trópicos, nomeadamente o capítulo $\mathrm{V}$ em que se elabora uma breve, porém rica relação entre Duchamp e o xadrez, fazendo referências a várias de suas obras e inclusive a "histórica partida" disputada entre ele e Man Ray no filme Entr'acte. Outra informação relevante é o resgate que Antelo faz da relação da América com o xadrez, via Ruy López. Surpreende-nos saber que mesmo 5 séculos depois, a abertura Ruy López conhecida também por abertura espanhola (1. e4 e5 2. Cf3 Cc6 3. Bb5 ...) - ainda é usual nos torneios entre grandes-mestres, através de suas intricadas variantes para os dois lados.

22. HUGILL, Andrew. "Beckett, Duchamp and Chess in the 1930's", 1992, p. 4.

23. DUCHAMP apud. HUGILL, Andrew. "Beckett, Duchamp and Chess in the 1930's", 1992, p. 6. 
24. O empate em xadrez determina que nenhum jogador se sagrou vencedor, seja por mútuo acordo, por insuficiência de material que resulte em xeque-mate, ou por chegar-se a uma determinada posição passível de empate, como poderia ser o caso de Fin de Partie. A palavra empate carrega em si o étimo grego páthos que derivou em passio, -nis em latim. Com o surgimento dos programas de xadrez, e dos jogadores-robôs, imagina-se que todas as partidas de xadrez tenderiam ao empate. Mas esta afirmação é ridicularizada por grandes-mestres, tendo em vista que os milhões de jogadas calculadas por uma máquina é uma quimera para o cérebro de um simples ser-humano e, por isto, as sutilezas e as ramificações do jogo jamais serão esgotadas. Além disso, temos o aspecto psicológico do jogo, o qual se encontra mutilado, ou melhor, ausente mesmo, nesses robôs.

25. "The unique horror of the position described above finds expression in Beckett's play, in which Black (Hamm) haphazardly delays and frustrates White (Clov). Identification of these two characters with their respective chess colours is made easy by the symbolic attributes of both: Hamm is blind, hence unaware; in a wheelchair, hence restricted; wearing sunglasses, hence "black"; Clov is knowing, mobile and frustrated". In: HUGILL, Andrew. "Beckett, Duchamp and Chess in the 1930's", 1992, p. 7.
Na figura 1 abaixo, extraída do artigo de Hugill, podemos ver a configuração que faz parte do estudo de Duchamp e Halberstadt, e que se supõe ser aquela que Beckett opera literariamente em Fin departie. Por motivos de sua dificuldade não entraremos em detalhes na posição, mas ela está totalmente explicada no artigo de Hugill, evidenciando quais são os lances corretos a serem jogados. Contudo, se o desfecho é vitória das brancas ou ainda empate, quando se trata de Beckett, dilata-se para além da mera empatia, da mesma partilha de sensações ${ }^{24}$. Haverá algum vencedor em Fin de partie? Qual o desenlace que aguarda o leitor após finalizar a partida, ou melhor, a leitura da peça?

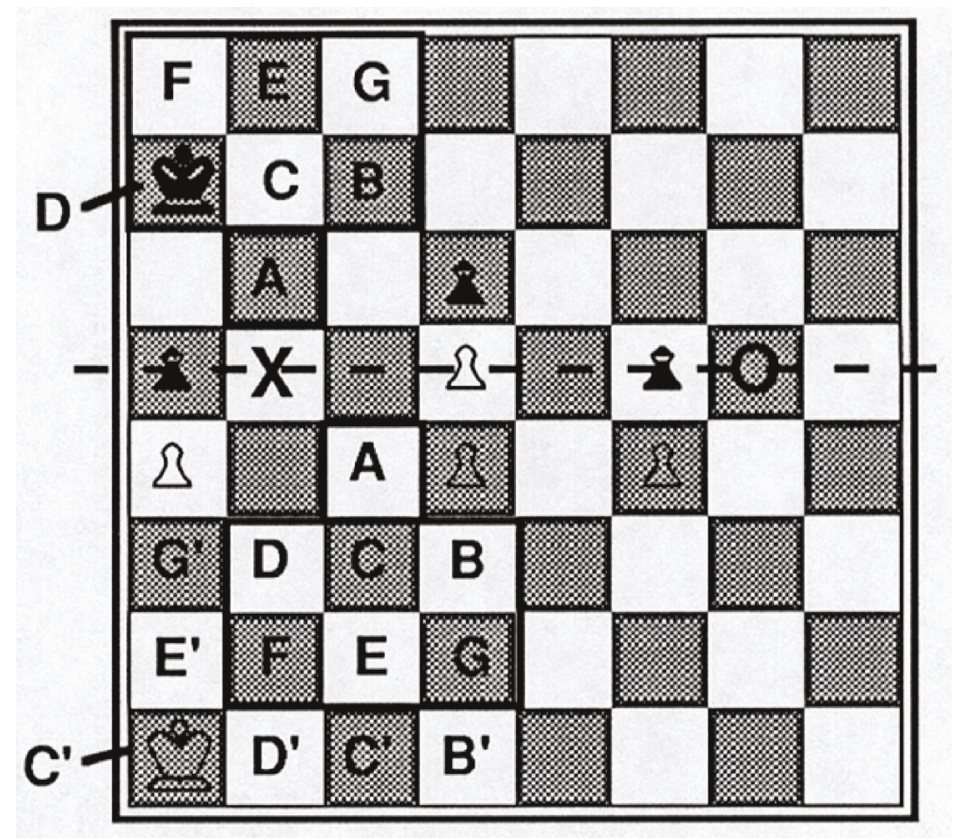

Fig. 1

Nesse artigo também nos valemos da sugestão bastante atraente de que Hamm - personagem cego, reduzido fisicamente à cadeira de rodas - representaria as peças negras - condenadas à derrota ou no máximo a um empate, enquanto Clov - o servo que, apesar de não enxergar muito bem, ainda obedece e está atrelado aos sons do apito de Hamm - representaria o exército branco ${ }^{25}$. Não obstante esta aproximação explícita com o jogo de xadrez desde o título da peça, gostaríamos de ir além desta comparação e verificar como se desenrolam os diálogos entre Hamm e Clov por um lado, e entre Nagg e Nell por outro. Diálogos que permeariam um certo vazio, um cenário destruído, da mesma forma que num jogo de xadrez cada lance abala o aparente equilíbrio anterior, sendo que o equilíbrio da disposição inicial das peças, isto é, aquele configurado antes mesmo de qualquer movimento por parte dos jogadores, representaria o equilíbrio par excellence. Sobre isto, vale a pena sublinhar dois 
parágrafos que nos comenta Martínez Estrada a respeito do que ocorre durante o jogo, os quais se encaixam com Fin de partie:

En ajedrez, cada idea tiene su compensación inmediata, cada fuerza su resistencia, cada afirmación su negación, cada signo positivo su signo contrario, pues la idea en el ajedrecista se compone de dos elementos en un trazo de ziszás.

Su situación en el tablero no es el juego del blanco o del negro, y sí el blanco-negro; cada movimiento es un problema inmediato y término de otro problema ulterior que plantea y resuelve desde los puntos antagónicos. ${ }^{26}$

Outra característica muito viva na literatura de Beckett é destacada igualmente nesta breve citação, em que os polos contrários estão em constante conflito, revelando um aspecto de contradição inerente ao jogo, bem como à literatura. Afirmamos isto baseados não apenas nos diálogos que se sucedem em Fin de partie, mas sobretudo a partir dos treze relatos que compõem Textes pour rien, publicados logo após a trilogia (Molloy, Malone meurt, L'innommable). Como exemplo, lemos: "How can I go on, I shouldn't have begun, no, I had to begin"; “There's my life, why not, it is one, if you like, if you must, I don't say no, this evening. There has to be one, it seems, once there is speech, no need of a story, a story is not compulsory, just a life, that's the mistake I made"27. Logo, o diálogo requer de ambos a participação nesse jogo de linguagem, apesar de que em Beckett a linguagem verbal parece sempre à beira do silêncio e do não-sentido, e principalmente da contradição, que encontra uma síntese perfeita nas últimas palavras de L'innommable: “je ne peux pas continuer, je vais continuer"28.

Partindo para a leitura da peça, verificamos que logo na descrição do cenário, Beckett apresenta-nos um aspecto de vazio e de destruição: "Intérieur sans meubles. Lumière grisâtre"29. Uma "paisagem do desastre", e se resgatarmos as palavras de Estragon seremos ainda mais radicais, pois ao invés da paisagem, preocupemo-nos com os vermes, com o que há debaixo da terra ${ }^{30}$.

Uma das definições de paisagem para o sociólogo alemão Georg Simmel é delimitar a natureza, que teoricamente representaria o uno ${ }^{31}$. Já para o crítico e escritor francês Maurice Blanchot, em L'écriture du désastre, marcado por ser um livro fragmentário contendo várias reflexões em torno dessa palavra désastre - que carrega consigo um aparente significado negativo ${ }^{32}$ nos diz logo na primeira frase: "Le désastre ruine tout en laissant tout en l'état"33. Enigmática frase que permite vislumbrar no desastre algo próximo do próprio desenvolvimento natural dos entes mundanos. Como pode o desastre, essa entidade tão abstrata, manter tudo como estava? Duas páginas adiante,
26. MARTÍNEZ ESTRADA, Ezequiel. Filosofía del ajedrez, 2008, p. 25.

27. BECKETT, Samuel. The complete short prose. 1929-1989, 1995, p. 100, 116.

\section{BECKETT, Samuel.}

L'innommable, 2008, p. 213. Na tradução ao inglês: "I can’t go on, I'll go on". In: BECKETT, Samuel. Three novels by Samuel Beckett. Molloy. Malone dies. The unnamable, 2009, p. 414.

29. BECKETT, Samuel. Fin de Partie, 2007, p.11. Na tradução ao inglês: "Bare interior. Grey light". In: BECKETT, Samuel. Endgame, 1990, p. 92

30. Em En attendant Godot, eis o que Estragon exclama: "Alors fous-moi la paix avec tes paysages! Parle-moi du soussol!"'. Na tradução ao inglês: "You and your landscapes! Tell me about the worms!".

\section{Em A Filosofoia da Paisagem} lê-se: "Um pedaço de natureza é, em rigor, uma contradição em si; a natureza não tem fracções; é a unidade de um todo. [...] Mas, para a paisagem, é justamente essencial a demarcação, o ser-abarcada num horizonte momentâneo ou duradouro". In: SIMMEL, Georg. A Filosofia da Paisagem, 2009, p. 6.

32. Efetuando uma rápida busca em um dicionário online, verificam-se algumas definições da palavra désastre: catastrophe, grand malheur, chose déplorable, échec total, ruine. Merece atenção a definição de échec total, já que a palavra échec em francês equivale a xeque em português, a mesma palavra utilizada para dizer que o rei está sendo atacado. Quando a situação é de xequemate, diz-se échec et mat, ou apenas mat. Mas tal definição de désastre como échec complet nos aproxima dessa morte simbólica do rei no tabuleiro, vida e xadrez novamente se encontram. 
33. BLANCHOT, Maurice.

L'écriture du désastre, 1980, p. 7.

34. Ibidem, p. 9.

35. BECKET'T, Samuel. Fin de Partie, 2007, p. 13. Na tradução ao inglês: "CLOV: [Fixed gaze, tonelessly.] Finished, it’s finished, nearly finished, it must be nearly finished". In: BECKETT, Samuel. Endgame, 1990, p. 93.

36. Ibidem, p. 14, 108. Na tradução ao inglês: "HAMM: Me - [he yawns] - to play". "Me to play. [...] Old endgame lost of old, play and lose and have done with losing". In: BECKETT, Samuel. Endgame, 1990, p. 93, 132.

37. A analogia entre xadrez e guerra é arcaica, não há novidade alguma nesta afirmação, mas o que muitas vezes fica de lado nos compêndios enxadrísticos é o caráter infinito de criação que este jogo proporciona, semelhante ao que ocorre no campo da literatura. Por exemplo, lemos: "Historically chess must be classed as a game of war. [...] The players have no assistance other than that afforded by their own reasoning faculties". In: MURRAY, H. J. R. A History of Chess, 2012, p. 37.
Blanchot continua contrapondo o anterior tout ao rien: "Rien ne suffit au désastre; ce qui veut dire que, de même que la destruction dans sa pureté de ruine ne lui convient pas, de même l'idée de totalité ne saurait marquer ses limites: toutes choses atteintes et détruites, les dieux et les hommes reconduits à l'abscence, le néant à la place de tout, c'est trop et trop peu pour le désastre" 34 .

Analogamente, com o xadrez e o momento do fim do jogo, restam poucas peças no tabuleiro de Beckett/Duchamp; especificamente um peão de cada cor e os respectivos reis, as demais peças já são "carne morta" - foram capturadas, em jargão enxadrístico. Enquanto a luz é cinza, e aqui poderíamos fazer uma comparação com aquilo que nos dissera Martínez Estrada, de que o jogo se desenrola a partir dos dois lados, mescladas, portanto, as peças brancas e negras, gerando uma cor grisácea. Da mesma forma, há desde a primeira fala uma ânsia em dar por terminado tudo aquilo que se desenrolará: "CLOV (regard fixe, voix blanche). - Fini, c'est fini, ça va finir, ça va peut-être finir" 35 .

Também é de sumo interesse perceber que as primeiras palavras proferidas por Hamm, entrecortadas por um bocejo, como se aquilo já estivesse se prolongando por um tempo indefinido, fazem referência ao jogo: "HAMM. - À - (baîllements) - à moi. (Un temps). De jouer". E no final da peça, novamente se alude ao jogo quando ele diz: "A moi [...] De jouer. [...] Vieille fin de partie perdue, finir de perdre" 36 .

De início somos convocados a revisitar o cenário de guerra que assolara a Europa sob as forças de Hitler, e inevitavelmente recordamos o encontro Duchamp-Beckett frente a frente diante de um tabuleiro de xadrez. Não sabemos o que ambos conversaram nesse encontro, mas é possível que tenham intercambiado ideias, e que Fin de partie encontre inspiração em 1940. Tampouco temos registro das partidas jogadas, apenas sabemos que se refugiaram em outro combate, em outra guerra, em outro cenário que também apelava à destruição ${ }^{37}$. Destruição que não invalida a possibilidade de criação, de potencialização das inúmeras possibilidades que se apresentam a cada peça movimentada. A guerra que atordoara Paris é levada a cabo em um tabuleiro na remota Arcachon, mas diferentemente de Hitler, os estrategistas em questão ampliarão a fronteira estabelecida pelo tabuleiro, vertendo em arte o jogo, criando, por assim dizer, um jogo através do jogo. Metajogo sempre relacionado com as infinitas possibilidades. Martínez Estrada afirma que no xadrez reduzimos as possibilidades, pois cada jogada é o aspecto concreto e único de inúmeras variantes que foram projetadas mentalmente, oriundas desse conflituoso caos de jogadas multiplicadas: 
La realidad, que en la vida está compuesta por infinitos factores, allí está concretada en un reducido número de piezas y casillas, y el ajedrecista no tiene el recurso de atribuir a la fatalidad y al destino la responsabilidad de sus actos, porque el futuro se presenta ante sus ojos planteado categóricamente, sin más reservas que las que le impone la limitación de su aptitud mental. Y aun cuando las fichas posean la infinita posibilidad combinativa de los números y las letras algebraicas, es ya mucho haber logrado reducir a una expresión finita en una pequeña zona del mundo, esse caos indeterminado y amorfo en que nos agitamos y vivimos. ${ }^{38}$

O escritor argentino é enfático neste excerto, afirmando que o destino não afeta o jogo de xadrez. Obviamente cada jogada depende da escolha do jogador, mas não podemos esquecer que antes de efetuar o lance material, isto é, literalmente com a mão ${ }^{39}$, ocorre uma série de reflexões virtuais que são acionadas pelo limite do cálculo humano, e o mais incrível é que, enquanto devo pensar para mover uma das minhas peças, devo levar em consideração as possíveis respostas de meu adversário. E é aqui que a finitude humana encontra obstáculo, pois enquanto as atuais máquinas de xadrez podem calcular milhões de jogadas, o intelecto humano limita-se a algumas unidades. Sendo assim, a intuição entra em jogo, um momento de inspiração em que o jogador observa a distribuição de um determinado conjunto de peças e rapidamente consegue "ver" uma sequência de lances. Como se aquela massa confusa adquirisse um ordenamento preciso que conduzisse ao xeque-mate. Muitas vezes, um erro de cálculo é fatal, e toda aquela emoção e convicção de vitória resulta em frustração. Enfim, pode-se afirmar que cada jogada, cada decisão do jogador, é um problema que transforma o caos precedente em um novo caos. Caos e gás, palavras próximas, e que se direcionam ao máximo de entropia.

Direcionando nossa reflexão para suas linhas finais, aproveitamos a palavra entropia para concluir o que aqui quisemos expor. Se, como apontado anteriormente, Clov representa as peças brancas e se aproxima da vitória, embora vagarosamente, ele buscaria ordenar sua posição no tabuleiro:

CLOV. - De l'ordre. (Il se redresse. Avec élan.) Je vais tout débarrasser!

Il se remet à ramasser.

HAMM. - De l'ordre!

CLOV (se redressant). - J'aime l'ordre. C'est mon rêve. Un monde où tout serait silencieux et immobile et chaque chose à sa place dernière, sous la dernière poussière. ${ }^{40}$

A descrição de Clov aproxima-se muito do que Erwin Schrödinger, físico austríaco, escrevera em seu livro publicado em
38. MARTÍNEZ ESTRADA, Ezequiel. Filosofía del ajedrez, 2008, p. 31.

39. Observe-se como a mão é importante no jogo, pois a partir do momento em que se toca a peça não há a possibilidade de retornar ou anular o lance, "toucher jourer!" é uma das regras cabais do jogo.

40. BECKETT, Samuel. Fin de Partie, 2007, p. 76. Na tradução ao inglês: "CLOV: Putting things in order. [He straightens up. Fervently]. I'm going to clear everything away! [He starts picking up again]. HAMM: Order! CLOV: [Straightening up]. I love order. It's my dream. A world where all would be silent and still and each thing in its last place, under the last dust". In: BECKETT, Samuel. Endgame, 1990, p. 120. (Grifo nosso). 
41. SCHRÖDINGER, Erwin. What is life?., 1996, p. 69.

42. Ibidem, p. 69.

43 O próprio Schrödinger propõe um tempo indefinido ao empregar as reticências: "Theoretically, it is very often not yet an absolute equilibrium, not yet the true maximum of entropy. But then the final approach to equilibrium is very slow. It could take anything between hours, years, centuries...". In: SCHRÖDINGER, Erwin. What is life? 1996, p. 69, 70.

44. BECKETT, Samuel. The complete short prose. 1929-1989, 1995, p. 70.

45 BECKETT, Samuel. Fin de Partie, 2007, p. 109. Na tradução ao inglês: "Moments for nothing, now as always, time was never and time is over, reckoning closed and story ended”. In: BECKET'T, Samuel. Endgame, 1990, p. 133.
1944 - um ano antes do fim da guerra, da pausa, da suposta paz. O título do livro é What is life?, tema caro ao escritor irlandês. Vejamos o que ele nos diz sobre a definição de vida:

What is the characteristic feature of life? When is a piece of matter said to be alive? When it goes on 'doing something', moving, exchanging material with its environment, and so forth, and that for a much longer period than we would expect an inanimate piece of matter to 'keep going' under similar circumstances. ${ }^{41}$

A definição de um sistema "não vivo" surge em seguida:

When a system that is not alive is isolated or placed in a uniform environment, all motion usually comes to a standstill very soon as a result of various kinds of friction; differences of electric or chemical potential are equalized, substances which tend to form a chemical compound do so, temperature becomes uniform by heat conduction. After that the whole system fades away into a dead, inert lump of matter. A permanent state is reached, in which no observable events occur. The physicist calls this state of thermodynamical equilibrium, or of 'maximum entropy'. ${ }^{42}$

Desde a perspectiva da física, esta definição de máxima entropia, de imobilidade total, Beckett, especificamente Fin de partie, pode ser lida como uma peça que vai de encontro à imobilidade. Se a hipótese de que Hamm e Clov são os reis preto e branco respectivamente, enquanto os progenitores de Hamm são os peões, o jogo de xadrez e este momento específico do fim de jogo, estudado na década de 1930 por Duchamp e Halberstadt, representariam em potência, a eterna repetição do estado de máxima entropia, num ir e vir incessante. Deve ser frisado que esse estado não ocorre rapidamente, pode demorar anos, séculos, e por que não arriscar, a eternidade ${ }^{43}$. Duração esta que confunde a "voz desencarnada" beckettiana em Texts for Nothing: "How long have I been here, what a question, I've often wandered. And often I could answer, an hour, a month, a year, a century, depending on what I meant by here, and me, and being" ${ }^{4}$.

Semelhante ao jogo de xadrez, o xeque-mate seria a ausência total de movimento para o monarca, representaria sua morte, seu grau máximo de entropia. Assim, Beckett teria posto em palavras o momento crucial de uma partida de xadrez. Eis um excerto do longo monólogo final de Hamm que indica bem o quisemos destacar neste trabalho: "Instants nuls, toujours nuls, mais qui font le compte, que le compte, que le compte y est, et l'histoire close" ${ }^{45}$. 


\section{Referências}

ANTELO, Raul. Maria com Marcel: Duchamp nos trópicos. Belo Horizonte: Editora UFMG, 2010.

BECKETT, Samuel. Endgame. London: Faber and Faber, 1990. The complete short prose. 1929-1989. New York: Grove

Press, 1995.

Fin de Partie. Paris: Éditions de Minuit, 2007.

L'innommable. Paris: Éditions de Minuit, 2008.

Three novels by Samuel Beckett. Molloy. Malone dies. The

unnamable. Tradução de Patrick Bowles em colaboração com o autor. New York: Grove Press, 2009.

BENJAMIN, Walter. Obras escolbidas. Magia e técnica, arte e política. Tradução Sergio Paulo Rouanet. São Paulo: Brasiliense, 1994.

BERGSON, Henri. L'énergie spirituelle. Essais et conférences. Paris: PUF, 1967.

BLANCHOT, Maurice. L'écriture du désastre. Paris: Gallimard, 1980.

BORGES, Jorge Luis. "Ajedrez". In: - Obra poética 2.

Madrid: Alianza Editorial, 2008.

CORNAVACA, Ramón (introdução, tradução e notas).

Presocráticos. Fragmentos I. Buenos Aires: Losada, 2008.

GONTARSKI, S. E. "Introdução e notas". In: BECKETT, Samuel. Samuel Beckett. The complete short prose. 1929-1989. New York: Grove Press, 1995.

HUGILL, Andrew. "Beckett, Duchamp and Chess in the 1930's". Disponível em: http://www.samuel-beckett.net/hugill. html. Acessado em 6/02/2016.

MARTÍNEZ ESTRADA, Ezequiel. Filosofía del ajedrez. Buenos Aires: Biblioteca Nacional, 2008.

MURRAY, H. J. R. A History of Chess. New York: First

Skyhorse, 2012.

PESSOA, Fernando. Obra poética. Rio de Janeiro: Nova Aguilar, 2005.

POE, Edgar Allan. The complete illustrated Works of Edgar Allan Poe. London: Bounty Books, 2003. 
SCHRÖDINGER, Erwin. What is life? Cambridge: Canto, 1996.

SIMMEL, Georg. A Filosofia da Paisagem. Tradução Artur Morão. Covilhã: LusoSofia, 2009.

VANDERVLIST, H. "Beckett, Duchamp and Chess: A Crossroads at Arcachon in the summer of 1940", Anglophonial Caliban, 33/2013.

WITTGENSTEIN, Ludwig. Philosophical Remarks. Tradução Raymond Hargreaves e Roger White. Chicago: Chicago Press, 1975.

Investigações Filosóficas. Tradução José Carlos Bruni. São Paulo: Abril, 1975.

Submissão: 19/04/2017

Aceite: 22/10/2017 